\title{
Hypothyroid Patients Encoding Combined MCT10 and DIO2 Gene Polymorphisms May Prefer L-T3 + L-T4 Combination Treatment - Data Using a Blind, Randomized, Clinical Study
}

\author{
Allan Carléa Jens Faber ${ }^{c, d}$ Rudi Steffensen ${ }^{b}$ Peter Laurberg ${ }^{a}$ \\ Birte Nygaard ${ }^{c, d}$ \\ a Department of Endocrinology, Aalborg University Hospital, Aalborg, Denmark; ${ }^{b}$ Department of Clinical \\ Immunology, Aalborg University Hospital, Aalborg, Denmark; ' ${ }^{C}$ Department of Endocrinology, Herlev Hospital, \\ University of Copenhagen, Copenhagen, Denmark; ${ }^{d}$ Faculty of Health and Medical Sciences, University of \\ Copenhagen, Copenhagen, Denmark
}

\section{Keywords}

Hypothyroidism · Thyroid failure $\cdot$ Single nucleotide

polymorphisms · L-T3 treatment · Randomized clinical trial

\begin{abstract}
Objectives: In previous studies, around half of all hypothyroid patients preferred levo-thyroxine (L-T4) + levo-triiodothyronine (L-T3) combination therapy, 25\% preferred T4, and $25 \%$ had no preference. The reason for this is yet to be explored. Methods: A total of 45 overtly autoimmune, hypothyroid patients - now euthyroid on $\geq 6$ months' L-T4 therapy - participated in a prospective, double-blind, cross-over study. The patients were randomized into 2 groups of either 3 continuous months' L-T4 therapy followed by 3 months' combination therapy or vice versa. In all periods, $50 \mu \mathrm{g} \mathrm{L-T4}$ was blindly replaced by either (identical) $50 \mu \mathrm{g}$ L-T4 or by 20 $\mu \mathrm{g}$ T3. L-T4 was hereafter adjusted to obtain normal serum TSH values. We investigated 3 single nucleotide polymorphisms (SNPs) on the type II iodothyronine deiodinase (DIO2) gene (rs225014 (Thr92Ala), rs225015, and rs 12885300 (ORFa-Gly3Asp)) and 1 SNP on the cellular membrane transport-facilitating monocarboxylate transporter (MCT10) gene
\end{abstract}

(rs17606253), and asked in which of the 2 treatment periods patients felt better (i.e., which treatment was preferred). $\boldsymbol{R} \boldsymbol{e}$ sults: 27 out of 45 patients (60\%) preferred the combination therapy. Two polymorphisms (rs225014 (DIO2, Thr92Ala) and rs17606253 (MCT10)) were combined yielding 3 groups: none vs. 1 of 2 vs. both SNPs present, and 42 vs. 63 vs. $100 \%$ of our patients in the 3 groups preferred the combined treatment (Jongheere-Terpstra trend test, $p=0.009$ ). Conclusion: The present study indicates that the combination of polymorphisms in DIO2 (rs225014) and MCT10 (rs17606253) enhances hypothyroid patients' preference for L-T4 + L-T3 replacement therapy. In the future, combination therapy may be restricted or may be even recommended to individuals harbouring certain polymorphisms.

(c) 2017 European Thyroid Association Published by S. Karger AG, Basel

\section{Introduction}

Hypothyroidism is very common and affects up to $10 \%$ of the female population [1]. Many patients do not feel well on standard levo-thyroxine (L-T4) treatment [25], and many patients may benefit from experimental

\section{KARGER}

(ㄷ) 2017 European Thyroid Association

Published by S. Karger AG, Basel
Allan Carlé, MD, $\mathrm{PhD}$

Department of Endocrinology

Aalborg University Hospital

DK-9000 Aalborg (Denmark)

E-Mail carle@dadlnet.dk 
treatment with combined levo-triiodothyronine (L-T3) + L-T4 preparations [6]. In the 2012 European Thyroid Association guidelines for the use of L-T4 and L-T3 in the treatment of hypothyroidism, Wiersinga et al. [6] reviewed 5 cross-over studies [7-11] and showed that $48 \%$ of all hypothyroid patients preferred the L-T3 + L-T4 combination therapy, $27 \%$ preferred L-T4 monotherapy, and $25 \%$ had no preference. No study has ever explained why so many patients prefer L-T3. In the meta-analysis by Grozinsky-Glasberg et al. [12], no difference was observed in symptom scores or various serum lipid profiles in those treated with L-T3 + L-T4 versus those treated with L-T4 alone. Almost 30 years ago, Carr et al. [13] reported better well-being in patients treated with a supraoptimal dose of $50 \mu \mathrm{g} \mathrm{L}$-T4. However, they had all serum TSH values of $<0.2 \mathrm{mU} / \mathrm{L}$, and were thus slightly overtreated.

Several other studies, in which patients were treated with a high dose of thyroid hormone with subsequently low serum TSH values, support these findings $[9,14]$. On the other hand, no differences in hypothyroid symptoms, quality of life, or cognitive function were seen in a doubleblind, randomized, clinical trial with cross-over design on 52, L-T4-treated, hypothyroid patients receiving $3 \mathrm{~L}-\mathrm{T} 4$ doses in random order for 8 weeks: usual dose, $25 \mu \mathrm{g}$ less, or $25 \mu \mathrm{g}$ more resulting in serum TSH values of $2.8 \pm 0.4$, $1.1 \pm 0.2$, and $0.3 \pm 0.1 \mathrm{mU} / \mathrm{L}$, respectively $(p<0.001)$. Walsh et al. [7] also studied hypothyroid patients with biochemically restored euthyroidism due to L-T4 substitution and found that the group of patients dissatisfied with their treatment had the same serum TSH, T3, and T4 concentrations as the patients having no complaints. A different co-morbidity status could perhaps explain some of the difference [7]. Weight loss may also be part of the explanation [2, 14-16], but although statistically significant, the weight loss in L-T3 + L-T4-treated patients (vs. standard L-T4 monotherapy) was shown to be only very modest [12].

Differential local expression and activity of iodothyronine deoidinases and thyroid hormone transmembrane transporters may be an explanation. Panicker et al. [17] showed that hypothyroid patients harbouring the CC genotype of the type II iodothyronine deiodinases (DIO2) rs 225014 polymorphism, seen in $16 \%$ in a populationbased study from the UK, had worse baseline general health scores and did also benefit more on L-T3 + L-T4 combination therapy compared to patients harbouring the wild type (WT) alleles. However, the serum T3 and T4 levels did not differ between WT and CC polymorphism patients in that study. This indicates that perhaps pa- tients' preference for one therapy form over the other may be explained by local intracerebral factors, again perhaps influenced by different gene expressions of $\mathrm{DIO} 2$ and/or the thyroid hormone transporters. Several gene polymorphisms may contribute to the understanding of the different experiences reported by hypothyroid patients.

We investigated 3 polymorphisms in the DIO2 genes: rs225014 known as Thr92Ala, rs22501, and rs12885300 originally entitled D2 ORFa-Gly3Asp, which may affect the intracerebral T4 to T3 conversion. We also investigated the role of the MCT10 rs17606253 polymorphism, which may affect the transport of thyroid hormones into the brain. MCT10 is a T-type aromatic amino acid transporter known both as solute carrier family 16 aromatic amino acid transporter member 10 (SLC16A10) and also known as T-type amino acid transporter (TAT1). MCT10 is a member of a family of plasma membrane amino acid transporters that mediate the $\mathrm{Na}^{(+)}$-independent transport of aromatic amino acids across the plasma membrane. However, MCT10 has also been found to transport thyroid hormones across membranes [18]. The MCT10 polymorphism has not been investigated as extensively as the MCT8 polymorphism. However, the MCT8 and MCT10 transporters have similar structures [19], wide tissue distributions [20], and facilitate both the uptake and efflux of T3 and T4 [21]. MCT10 has been shown to transport T3 better than the MCT8 transporter [22]. To our knowledge, no other study has ever elaborated whether polymorphisms in the MCT10 gene may explain why some patients have better treatment response when L-T3 is combined with the classic L-T4 treatment.

\section{Subjects and Methods}

The present study is based on patients previously recruited to a Danish, randomized, double-blind, cross-over study [8]. For the present study, the original patient group was re-invited to a blood test for genetic testing.

\section{Sample Population}

The precise criteria for selecting 59 patients in the original study have been previously outlined [8]. In short, patients diagnosed with overt autoimmune hypothyroidism (TSH values $>20$ $\mathrm{mU} / \mathrm{L}$, serum T4 $<60 \mathrm{nmol} / \mathrm{L}, \mathrm{TPOAb}>60 \mathrm{mU} / \mathrm{L}$, no other evident nosological type of thyroid failure than spontaneous hypothyroidism [1]), between 18 and 76 years of age, who had been treated with L-T4 substitution dose, and with a 6-month stable serum TSH value (range of 0.1-5.0 mU/L, determined on morning blood samples before taking thyroid hormone substitution) were included in the original study. Exclusion criteria were a previous L-T3 treatment or a current or planned pregnancy. 
As previously described in details [8], patients were block randomized into 1 of 2 treatment arms. One group of patients had 50 $\mu \mathrm{g}$ of their usual L-T4 dose replaced by $20 \mu \mathrm{g}$ L-T3 for a 12 -week period and were then shifted into their usual L-T4 dose for another 12 weeks. The other group initially continued on their usual dose - blind by a " 50 to $50 \mu \mathrm{g}$ L-T4 shift" - for 12 weeks, after that, $50 \mu \mathrm{g}$ of their usual L-T4 dose was replaced by $20 \mu \mathrm{g}$ L-T3 for another 12 weeks. As previously stated [8], within the 12-week period, the L-T4 doses were further adjusted to obtain stable serum $\mathrm{TSH}$ values between 0.1 and $5.0 \mathrm{mU} / \mathrm{L}$.

\section{Questionnaires}

Participants filled out a questionnaire obtaining information on their general well-being (Short Form Survey, SF-36). They were asked for the treatment period in which they felt better. The results were blinded until the time of statistical analyses. Then, it was revealed whether they preferred the combined L-T3 + L-T4 treatment, L-T4 monotherapy alone, or had no preference.

\section{Single Nucleotide Polymorphism Genotyping}

All patients from the original study were re-invited to a blood test for genetic testing. Of those 59, 45 patients gave blood for single nucleotide polymorphism (SNP) genotyping. Genomic DNA was extracted from EDTA-treated peripheral blood using the QiaSymphony SP System (Qiagen, Hilden, Germany). The predesigned TaqMan SNP Genotyping Assays ${ }^{\circledR}$ C_15819951_10, C_568127_10, C_31755153_30, and C_33173970_10 (Applied Biosystems, Foster City, CA, USA) were used to investigate the 4 SNPs - of which 3 are located in the DIO2 gene (rs225014 (Thr92Ala), rs225015, and rs12885300 (ORFa-Gly3Asp)), and 1 is located in the MCT10 gene (rs17606253). Allelic discrimination plots clearly distinguish between WT, heterozygous polymorphism alleles, and homozygous polymorphism alleles [23].

\section{Serum TSH, T3 and T4 Analyses}

Serum levels of TSH and peripheral thyronines (T3 and T4) were all measured on blood samples drawn in the morning. The DPC Immulite ${ }^{\circledR} 2500$ (Siemens, DPC, Bad Nauheim, Germany) was used for measuring serum TSH levels (normal range 0.4-4.0 $\mathrm{mU} / \mathrm{L}$, inter- and intra-assay coefficients of variation (CVs) of 5\%), total T3 (normal range $1.0-2.6 \mathrm{nmol} / \mathrm{L}, \mathrm{CVs} 4 \%$ ), and total T4 (normal range 60-140 nmol/L, CVs 5\%). The total T3 and T4 concentrations will be referred to as $\mathrm{T} 3$ and $\mathrm{T} 4$ in this paper, respectively. Conversion factors from SI (nmol/l) to American (ng/dl) units are $\times 0.0778$ for total T4 and $\times 0.0643$ for total T3. TPOAb (normal range $<60 \mathrm{kU} / \mathrm{L}$, CVs $4 \%$ ) was measured by TPOAbDYNO test (previously BRAHMS, now Thermo Fisher).

\section{Statistical Analysis}

We used IBM Statistical Package for Social Sciences version 15.0 (SPSS, Chicago, IL, USA) for statistical analyses. Means and standard error of means (SEM) or when appropriate medians and interquartile range ( 25 to $75 \%$ range) were calculated. The Fisher exact $t$ test, independent sample $t$ test (Gaussian-distributed values), Mann-Whitney U test (no Gaussian distribution), and Wilcoxon test (no Gaussian distribution, dependent test between 2 groups) were used for intergroup comparisons. Odds ratios (OR) with $95 \%$ confidence intervals was used to describe the association between the various SNP distributions and L-T3 treatment preferences. Linear by linear test and Jongheere-Terpstra test were used for trend testing. The Hardy-Weinberg equation was tested under the assumption of an additive model, with a null hypothesis of no linkage and no association [24]. A $p$ value $<0.05$ was considered statistically significant. Minor allele frequencies (MAF) were calculated according to standard procedures.

\section{Ethical Approval}

The project was accepted by the Danish Medicines Agency (No. 2612-1939), the Danish National Committee on Biochemical Research Ethics (No. KA02022ms and H-1-22011-145), and the Danish Data Protection Agency (No. 2002-41-2236).

\section{Results}

Of the 59 patients, who originally attended the doubleblind, randomized, clinical study [8], 45 participants accepted the invitation for a second visit and blood test for genotyping. Of these, 27 patients (60\%) preferred the combined L-T3 + L-T4 treatment, 7 patients preferred the L-T4 monotherapy, whereas 11 patients had no preference. The baseline characteristics and serum concentrations of TSH, $\mathrm{T} 3$, and T4 during the study are depicted in Table 1. A comparison between those preferring the combined L-T3 $+\mathrm{L}-\mathrm{T} 4$ treatment with the rest of the patients revealed no difference in any of the parameters investigated. In particular, no difference was observed in serum TSH, T3, or T4 levels between those 2 groups - a finding consistent at the time of diagnosis, at the time of randomization which was performed when patients had stable thyroid function during standard L-T4 treatment, and during both the L-T4 monotherapy and the combined L-T3 + L-T4 treatment. However, both groups of patients had significantly higher T3 (2.40 vs. $1.60 \mathrm{nmol} / \mathrm{L}, p<0.001$, Wilcoxon test) and lower T4 (75 vs. $126 \mathrm{nmol} / \mathrm{L}, p<0.001$ ) but equal serum TSH levels ( 0.80 vs. $1.06 \mathrm{mU} / \mathrm{L}, p=0.38$ ) during the period in which they were treated with L-T3 + L-T4 combination therapy versus L-T4 monotherapy.

The distribution of the alleles of the 3 DIO2 SNPs (rs225014, rs225015, and rs12885300) and the MCT10 gene (rs17606253) is shown in Table 2. No deviation from the Hardy-Weinberg equation was observed. The polymorphisms investigated were rather common, judged by their MAF varying between 17 and $47 \%$.

The association between the 4 gene polymorphisms and the patients' preference for L-T3 + L-T4 combination versus L-T4 monotherapy is depicted in Figure 1. Calculations were performed under the assumption of an additive model comparing WT (no polymorphism alleles) with non-WT patients ( 1 or 2 polymorphism alleles present). Patients preferring the combination therapy had a 
Table 1. Patient characteristics according to treatment preference (L-T3 + L-T4 vs. L-T4) of hypothyroid patients $(n=45)$

\begin{tabular}{|c|c|c|c|c|}
\hline Characteristics & All & $\begin{array}{l}\text { L-T3 preference } \\
(n=27)\end{array}$ & $\begin{array}{l}\text { No L-T3 preference } \\
(n=18)\end{array}$ & $p$ value \\
\hline \multicolumn{5}{|l|}{ At diagnosis } \\
\hline Women/Men ${ }^{\mathrm{A}}$ & $42 / 3$ & $25 / 2$ & $17 / 1$ & $0.65^{\mathrm{D}}$ \\
\hline Age, years ${ }^{\mathrm{A}}$ & $46.7 \pm 1.62$ & $45.6 \pm 2.21$ & $48.4 \pm 2.35$ & $0.39^{\mathrm{E}}$ \\
\hline Serum TSH, mU/L $\mathrm{L}^{\mathrm{B}, \mathrm{C}}$ & $58(35-100)$ & $69(39-135)$ & $50(30-82)$ & $0.22^{\mathrm{F}}$ \\
\hline Serum TPOAb, kU/L ${ }^{A}, \mathrm{C}$ & $1,142(233-3,000)$ & $1,271(206-3,000)$ & $916(225-2,110)$ & $0.46^{\mathrm{F}}$ \\
\hline \multicolumn{5}{|l|}{ Before randomization } \\
\hline $\mathrm{BMI}^{\mathrm{A}}$ & $25.9 \pm 0.54$ & $26.4 \pm 0.80$ & $25.1 \pm 0.57$ & $0.20^{\mathrm{E}}$ \\
\hline Height, $\mathrm{cm}^{\mathrm{A}}$ & $170 \pm 1.01$ & $171 \pm 1.46$ & $170 \pm 1.30$ & $0.55^{\mathrm{E}}$ \\
\hline Weight, $\mathrm{kg}^{\mathrm{A}}$ & $75.1 \pm 1.68$ & $76.9 \pm 2.47$ & $72.3 \pm 1.87$ & $0.35^{\mathrm{E}}$ \\
\hline Serum TSH, mU/L ${ }^{A}$ & $1.12(0.63-2.22)$ & $1.65(0.55-2.85)$ & $0.95(0.77-1.34)$ & $0.15^{\mathrm{F}}$ \\
\hline Serum T3, nmol/L & $1.65(1.30-2.00)$ & $1.75(1.28-2.00)$ & $1.55(1.28-1.93)$ & $0.50^{\mathrm{F}}$ \\
\hline Serum T4, nmol/L & $125(101-149)$ & $127(103-153)$ & $124(89-152)$ & $0.73^{\mathrm{F}}$ \\
\hline $\mathrm{T} 3 / \mathrm{T} 4$ ratio, $\times 10^{-3}$ & $12.9(11.3-15.3)$ & $13.6(11.6-15.5)$ & $12.2(10.4-14.9)$ & $0.24^{\mathrm{F}}$ \\
\hline \multicolumn{5}{|l|}{ On L-T3 + L-T4 therapy } \\
\hline Weight, $\mathrm{kg}^{\mathrm{A}}$ & $74.8 \pm 1.73$ & $76.7 \pm 2.56$ & $72.0 \pm 1.88$ & $0.36^{\mathrm{E}}$ \\
\hline Serum TSH, mU/L & $0.80(0.31-1.75)$ & $0.86(0.37-2.14)$ & $0.65(0.24-1.70)$ & $0.39^{\mathrm{F}}$ \\
\hline Serum T3, nmol/L & $2.40(1.78-3.20)$ & $2.80(1.75-3.25)$ & $2.30(1.75-3.05)$ & $0.84^{\mathrm{F}}$ \\
\hline Serum T4, nmol/L & $74.5(54.3-101)$ & $71(56-105)$ & $83(51-104)$ & $0.85^{\mathrm{F}}$ \\
\hline T3/T4 ratio, $\times 10^{-3}$ & $32.2(23.9-44.6)$ & $28.6(23.0-47.7)$ & $33.8(26.4-40.8)$ & $0.65^{\mathrm{F}}$ \\
\hline \multicolumn{5}{|l|}{ On L-T4 monotherapy } \\
\hline Weight, $\mathrm{kg}^{\mathrm{A}}$ & $75.7 \pm 1.83$ & $77.5 \pm 2.70$ & $73.0 \pm 2.05$ & $0.41^{\mathrm{E}}$ \\
\hline Serum TSH, mU/L & $1.06(0.66-2.00)$ & $1.22(0.68-2.10)$ & $0.98(0.58-1.95)$ & $0.30^{\mathrm{F}}$ \\
\hline Serum T3, nmol/L & $1.60(1.30-1.98)$ & $1.75(1.45-2.30)$ & $1.55(1.30-1.90)$ & $0.94^{\mathrm{F}}$ \\
\hline Serum T4, nmol/L & $126(96-149)$ & $120(97-149)$ & $130(92-150)$ & $0.28^{\mathrm{F}}$ \\
\hline $\mathrm{T} 3 / \mathrm{T} 4$ ratio, $\times 10^{-3}$ & $13.3(11.7-15.1)$ & $13.6(12.5-15.2)$ & $12.3(10.6-15.1)$ & $0.13^{\mathrm{F}}$ \\
\hline
\end{tabular}

Values are mean \pm SEM or median (interquartile range) unless indicated otherwise.

${ }^{A}$ Information at randomization. ${ }^{B}$ Information when hypothyroidism was diagnosed. ${ }^{\mathrm{C}}$ Missing information on TSH at diagnosis $(n=11)$ and TPOAb $(n=1)$, T3 at inclusion/after L-T3 combination therapy (after L-T4 monotherapy $(n=1 / 3 / 1)$, T4 at inclusion $(n=$ $2 / 3 / 1)$, weight at inclusion $(n=14)$.

Tests for comparisons: ${ }^{\mathrm{D}}$ Fisher exact $t$ test; ${ }^{\mathrm{E}}$ independent sample $t$ test (Gaussian distributed values), ${ }^{\mathrm{F}}$ Mann-Whitney U test (no Gaussian distribution).

Conversion factors from SI (nmol/L) to American (ng/dL) units are $\times 0.0778$ for total T4 and $\times 0.0643$ for total T3.

Table 2. Distribution of iodothyronine deiodinase (DIO2) and monocarboxylate transporter (MCT10) single nucleotide polymorphisms (SNPs) in hypothyroid patients $(n=45)$

\begin{tabular}{lllll}
\hline & $\begin{array}{l}\text { SNPs, } n \\
\text { (wild type) }\end{array}$ & $\begin{array}{l}\text { Hetero- } \\
\text { zygous, } n \\
\text { (wild type; } \\
1 \text { SNP) }\end{array}$ & $\begin{array}{l}\text { Homo- } \\
\text { zygous, } n \\
\text { (double } \\
\text { SNP) }\end{array}$ & $\begin{array}{l}\text { Hardy- } \\
\text { Weinberg } \\
\text { equation }\end{array}$ \\
\hline DIO2 & & & & \\
rs225014 & $26(\mathrm{TT})$ & $18(\mathrm{CT})$ & $1(\mathrm{CC})$ & 0.29 \\
rs225015 & $23(\mathrm{GG})$ & $18(\mathrm{AG})$ & $4(\mathrm{AA})$ & 0.86 \\
rs12885300 & $14(\mathrm{CC})$ & $20(\mathrm{CT})$ & $11(\mathrm{TT})$ & 0.47 \\
rs225011 & $41(\mathrm{TT})$ & $6(\mathrm{GT})$ & $0(\mathrm{GG})$ & \\
MCT10 & & & & \\
rs17606253 & $31(\mathrm{TT})$ & $13(\mathrm{CT})$ & $1(\mathrm{CC})$ & 0.79 \\
\hline
\end{tabular}

6.40 (1.06-49.7) higher odds for harbouring at least 1 polymorphism in the rs17606253 (MCT10) gene $(p=$ 0.018). Similarly, patients who felt better during L-T3 + L-T4 combination therapy had a $2.80(0.66-12.3)$ borderline higher odds for harbouring at least 1 polymorphism in the rs225014 (DIO2) gene $(p=0.11)$. Collinearity was observed between the 2 DIO2 polymorphisms rs225014 and $\mathrm{rs} 12885300(p<0.001)$.

Accordingly to standard procedures $[25,26]$, we combined the 2 gene polymorphisms with the highest OR suggesting an association with L-T3 treatment preference, namely the rs17606253 (MCT10) and the rs225014 (DIO2) polymorphism. Patients were classified into 3 groups: those with no polymorphism in neither of the 2 genes (WT in both genes, "double" WT, $n=19$ ), those 


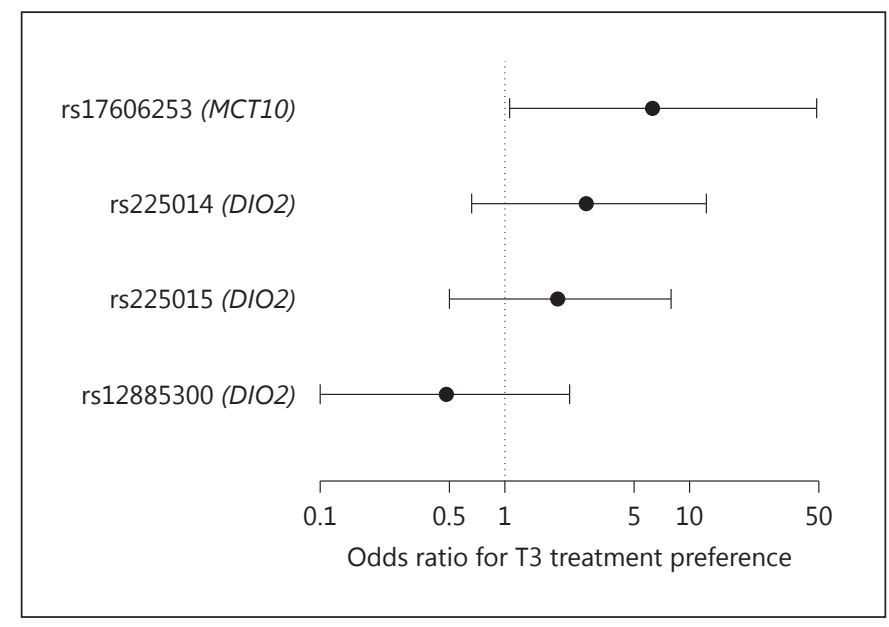

Fig. 1. Odds ratios (OR) for harbouring various single nucleotide polymorphisms (SNPs) in case of favouring the combined L-T3 + L-T4 over standard L-T4 treatment in hypothyroid patients $(n=$ $45)$. OR for the 4 SNPs investigated were: $6.40(1.06-49.7), p=$ 0.018 for $\mathrm{rs} 17606253$ (MCT10); $2.80(0.66-12.3), p=0.11$ for rs225014 (DIO2); 1.96 (0.50-7.94), $p=0.27$ for rs225015 (DIO2); and $0.49(0.10-2.24), p=0.29$ for rs12885300 (DIO2). Test for collinearity: rs 12885300 vs. rs225014, $p<0.001$; all other combinations, $p>0.05$.

with a polymorphism in only 1 of the 2 genes (heterozygous as well as homozygous, $n=19$ ), and those harbouring polymorphisms in both the rs17606253 (MCT10) and the rs225014 (DIO2) gene $(n=7)$. In the group of "double" WT patients with no polymorphism present, $42.1 \%$ preferred the combination L-T3 + L-T4 therapy (Fig. 2). The corresponding prevalences were 63.2 and $100 \%$ in the groups with polymorphisms present in 1 and 2 genes. Trend tests indicated a statistically significant dose-response pattern ( $p$ values between 0.009 and 0.011 ).

\section{Weight Changes}

The 45 patients included in the present study had an average weight (mean \pm SEM) of $75.1 \mathrm{~kg}( \pm 1.68)$ at the time of randomization i.e. after half a year with normal thyroid status (Table 1). Only modest and statistically nonsignificant weight differences were observed between the various groups: a $0.78( \pm 0.23) \mathrm{kg}$ higher weight when treated with L-T4 versus L-T3 + L-T4 combination, a 0.95 $( \pm 0.28) \mathrm{kg}$ higher weight on L-T4 only (vs. on L-T3 + $\mathrm{L}-\mathrm{T} 4)$ in those preferring L-T3. The last finding was not statistically different $(p=0.28)$ from the modest weight differences observed in patients not preferring L-T3 who weighed $0.51( \pm 0.38) \mathrm{kg}$ more on L-T4 monotherapy compared to combination therapy.

Hypothyroidism, MCT10 and DIO2 Gene

Polymorphisms, and L-T3 + L-T4

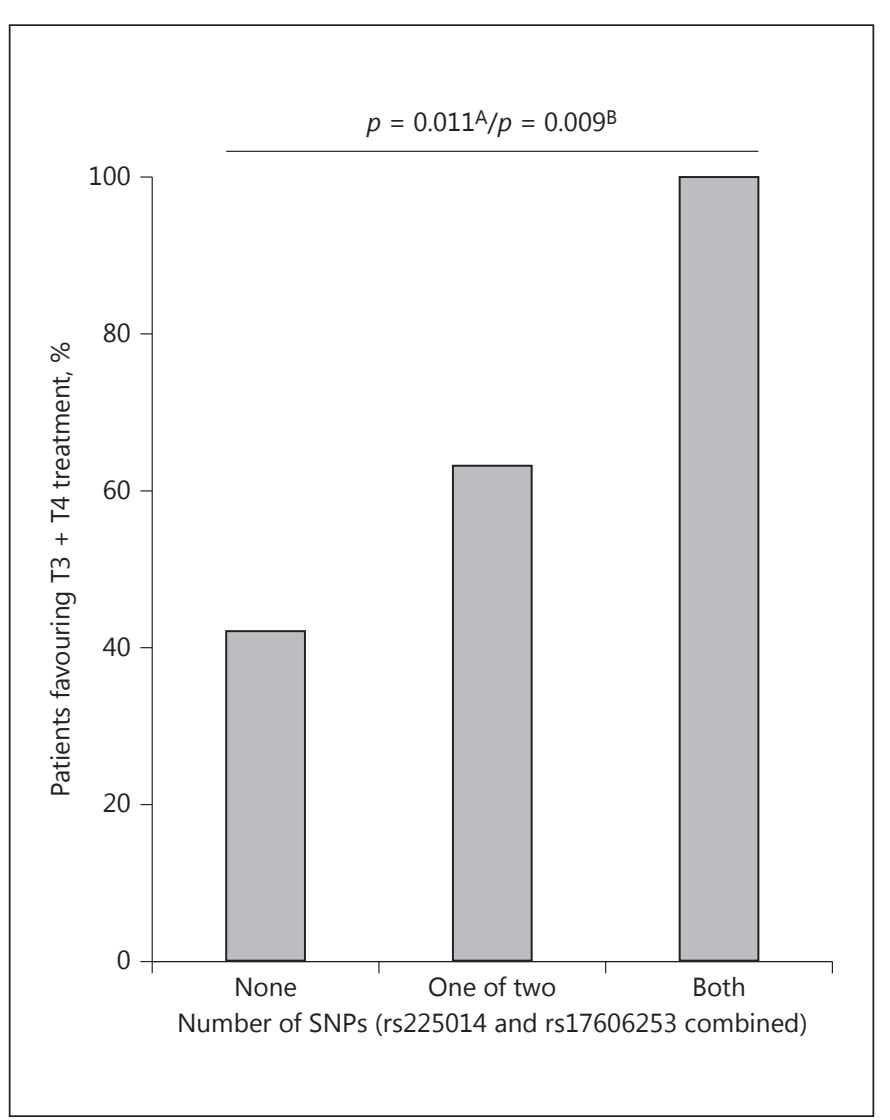

Fig. 2. Patients' preference for the combined L-T3 + L-T4 treatment over no preference was depicted according to their MCT10 and DIO2 gene polymorphisms. Three groups of patients were compared: those with wild-type nucleotides on both rs 225014 (DIO2) and rs17606253 (MCT10) genes, those with 1 of the 2 possible polymorphisms, and those with both polymorphisms present (number of patients in the 3 groups were 19, 19, and 7). In the 3 groups 8,12 , and 7 patients $(42.1,63.2,100 \%)$ preferred the combined L-T3 + L-T4 treatment. Linear by linear test $\left({ }^{\mathrm{A}}\right)$ and Jongheere-Terpstra test $\left({ }^{B}\right)$ were used for testing the dose-response association.

\section{Discussion}

In this randomized, clinical, cross-over trial encompassing hypothyroid patients treated with L-T4 monotherapy or with L-T3 + L-T4 combination therapy, we demonstrated that subjects harbouring the combination of 2 polymorphisms (rs225014 encoding the DIO2 enzyme and rs12885300 encoding the MCT10 transporter) were more prone to benefit from the experimental L-T3 + L-T4 combination therapy. This is the first study showing that the MCT10 polymorphism is associated with a preference for combined L-T3 + L-T4 treatment. 
Treatment Preferences - Well-Being

In the 2005 study by Appelhof et al. [27] encompassing hypothyroid patients on a stable L-T4 dose for more than 6 months, no differences in well-being, neurocognitive effect, or treatment preference were found between subjects harbouring different rs225014 or rs12885300 polymorphisms (both DIO2 SNPs also investigated in the present study). However, the authors apparently did not try to combine any of the genes under investigation in their statistical work-up.

In the 2009 study by Panicker et al. [17], 16 type I, II, and III deiodinase gene polymorphisms were investigated. Patients with SNPs in the $3 \mathrm{DIO} 2$ genes investigated (rs225011, rs225014, and rs225015) felt better when treated with the combination therapy compared to the standard L-T4 treatment [17]. However, all findings were borderline significant with $p$ values ranging from 0.02 to 0.06 , and the authors concluded that the results should be verified. This is the first study to replicate their findings.

\section{Thyroid Hormone Concentrations}

The results on serum $\mathrm{T} 3$ and $\mathrm{T} 4$ concentrations in medically substituted hypothyroid patients harbouring different blood-brain transmembrane and intracerebral iodothyronine deiodinase polymorphisms are highly inconsistent. Almost all studies have shown identical serum TSH and thyroid hormone concentrations in hypothyroid patients harbouring different DIO2 polymorphism in rs225014 [17, 25-37] and rs12885300 [27, 28, 30]. However, a few exceptions have also been published [25, 38, 39].

The role of various MCT10 polymorphisms is still in its research infancy, and more studies have been advocated for [19]. A few studies have demonstrated different serum thyroid hormone concentrations in subjects harbouring different rs17706253 (MCT10) polymorphisms $[19,40]$, but the findings are not consistent $[19,41]$.

\section{Body Weight}

As already mentioned, the small changes in body weight did not explain why some patients felt better on the experimental L-T3 + L-T4 combination therapy. This is in good line with the findings from the Grozinsky-Glasberg meta-analysis [12] which only showed very modest differences in body weight.

\section{Pathophysiological Mechanisms Involved}

This is the first study to evaluate the role of MCT10 polymorphisms on the clinical L-T3 + L-T4 treatment response in hypothyroid patients. The MCT10 polymorphism is not yet as extensively investigated as polymor- phisms in the MCT8 gene. However, Friesema et al. [18] demonstrated that MCT10 is at least as active as MCT8 in terms of in- and efflux of thyroid hormones with a preference for L-T3 over L-T4. MCT10 is expressed in many organs - also in the brain. It is also expressed in the small intestine [18], but our study does not indicate that patients with MCT10 polymorphisms may have different intestinal absorption with a subsequent lower hormone level in blood.

DIO2 is a cytosolic protein. It catalyzes the conversion of thyroxine $\left(3,5,3^{\prime}, 5^{\prime}\right.$-tetraiodothyronine, $\left.\mathrm{T} 4\right)$ to the biologically more active thyroid hormone (3,5,3'-triiodothyronine, T3) by outer ring $5^{\prime}$-deiodination. The DIO2 gene is widely expressed in the thyroid, placenta, pituitary, and brain [42]. Thus, it is responsible for the "local" production of T3 in brain tissue. Theoretically, the T3 concentration in brain cells may depend more on the MCT10 and DIO2 activity than on the $\mathrm{T} 3$ or $\mathrm{T} 4$ concentrations in blood.

A recently published paper has reviewed various studies, and it was concluded that an overall discrepancy between the symptom burden and thyroid hormone levels in overt hypothyroidism was present [43]. This was confirmed in a study comprising patients newly diagnosed with overt autoimmune hypothyroidism [44]. It is important to remember that the concentration of thyroid hormones in serum may not necessarily indicate the hormone status of all individual tissues.

\section{Implication}

Whereas the expression of the DIO1, the PDE8B, and to some extent also the thyroid hormone receptor may have a pivotal role in determining the serum T3 to T4 balance $[40,45]$, the results from the present study and others suggest that DIO2 and MCT activity may play a role in patients' response to thyroid hormone treatment. We have reported that the presence of combined rs17606253 (MCT10) and rs225014 (DIO2) gene polymorphisms may predict better outcome if hypothyroid patients are treated with the combined L-T3 + L-T4 regime.

Perhaps it will be possible in the future to individually tailor a specific treatment based on a patient's genetic composition. Patients harbouring certain polymorphisms may need additional L-T3 treatment to obtain better outcome. In the future, more polymorphisms will be studied. The study by Taylor et al. [46] indicated that uncommon polymorphisms (MAF $<1 \%$ ) may have a very large impact on the associations studied.

The relative importance of the thyroid hormone transporter in species may differ substantially [47] and so may 
their relative expression in various tissues and at different points of time during human life [48]. It has been claimed that the OATP1C1 gene is relatively less expressed in humans compared to other species and restricted to very specific areas of the human brain. The present study may indicate that MCT10 expression plays a large role in adult human life.

\section{Limitations}

A limitation of the present study and others searching for associations between SNPs and subject characteristics is the possibility of introducing false positive conclusions (type I error) [49]. We found $p$ values around $1 \%$ for the association between the 2 combined polymorphisms and treatment preference. However, this is just below the Bonferroni adjusted $p$ value of $1.3 \%\left(p=1-{ }^{4} \sqrt{ } 0.95\right.$ [50]).

In observational studies, an association does not necessarily imply causation. However, several of the Bradford-Hill criteria are met [51]. Firstly, the dose-response criterion is met (Fig. 2). Secondly, the biological mechanism for the finding is plausible as impaired MCT10-facilitated thyroid hormone influx may influence brain metabolism and may cause symptoms. Thirdly, an OR of 6 (for the MCT10 polymorphism) indicates a rather strong association, and interestingly positive findings were achieved with only 45 patients included in the study. Last, the fact that 2 previous studies $[17,27]$ have reported similar findings studying 3 of the potential 4 associations between DIO2 polymorphisms and preference of the L-T3 combination therapy also supports our findings.

The present study may hamper from selection bias. Of all hypothyroid patients treated in a population, some still have complaints despite biochemically restored euthyroidism. Some of these patients may seek help from new treatment modalities. Thus, the 45 patients included in the present study may be just a small and highly selected fraction of patients diagnosed with hypothyroidism.

\section{Conclusion}

We found that the combination of 2 polymorphisms in MCT10 (rs17606253) and DIO2 (rs225014) enhances hypothyroid patients' preference for L-T3 + L-T4 replacement therapy. Hopefully, these findings will be retested and perhaps also confirmed in future studies. If so, it may be possible in the future to genetically test and select those hypothyroid patients who may benefit from the combined L-T3 + L-T4 treatment. By such an approach, treatment of hypothyroidism may become individually tailored to fit all individuals harbouring different genetic compositions.

\section{Disclosure Statement}

The authors have no conflicts of interest to disclose. The funding received had no impact on study design and methods, data collection and analysis, or manuscript preparation.

\section{Author Contributions}

A.C., B.N., and P.L. had full access to all of the data in the study and take responsibility for the integrity of the data and the accuracy of the data analysis. Study concept and design: all authors. Data acquisition, analysis, or interpretation: all authors. Manuscript preparation: all authors.

\section{References}

1 Carlé A, Laurberg P, Pedersen IB, Knudsen N, Perrild H, Ovesen L, Rasmussen LB, Jorgensen T: Epidemiology of subtypes of hypothyroidism in Denmark. Eur J Endocrinol 2006;154:21-28.

2 Saravanan P, Chau WF, Roberts N, Vedhara K, Greenwood R, Dayan CM: Psychological well-being in patients on "adequate" doses of L-thyroxine: results of a large, controlled community-based questionnaire study. Clin Endocrinol (Oxf) 2002;57:577-585.

3 Ladenson PW: Psychological wellbeing in patients. Clin Endocrinol (Oxf) 2002;57:575576.
4 Wekking EM, Appelhof BC, Fliers E, Schene AH, Huyser J, Tijssen JG, Wiersinga WM: Cognitive functioning and well-being in euthyroid patients on thyroxine replacement therapy for primary hypothyroidism. Eur J Endocrinol 2005;153:747-753.

5 Walsh JP: Dissatisfaction with thyroxine therapy - could the patients be right? Curr Opin Pharmacol 2002;2:717-722.

-6 Wiersinga WM, Duntas L, Fadeyev V, Nygaard B, Vanderpump MP: 2012 ETA Guidelines: the use of L-T4 + L-T3 in the treatment of hypothyroidism. Eur Thyroid J 2012;1:55-71.
7 Walsh JP, Shiels L, Lim EM, Bhagat CI, Ward LC, Stuckey BG, Dhaliwal SS, Chew GT, Bhagat $\mathrm{MC}$, Cussons $\mathrm{AJ}$ : Combined thyroxine/ liothyronine treatment does not improve well-being, quality of life, or cognitive function compared to thyroxine alone: a randomized controlled trial in patients with primary hypothyroidism. J Clin Endocrinol Metab 2003;88:4543-4550.

8 Nygaard B, Jensen EW, Kvetny J, Jarlov A, Faber J: Effect of combination therapy with thyroxine (T4) and 3,5, $3^{\prime}$-triiodothyronine versus T4 monotherapy in patients with hypothyroidism, a double-blind, randomised cross-over study. Eur J Endocrinol 2009;161:895-902. 
9 Bunevicius R, Kazanavicius G, Zalinkevicius $\mathrm{R}$, Prange AJ Jr: Effects of thyroxine as compared with thyroxine plus triiodothyronine in patients with hypothyroidism. N Engl J Med 1999;340:424-429.

10 Escobar-Morreale HF, Botella-Carretero JI, Gomez-Bueno M, Galan JM, Barrios V, Sancho J: Thyroid hormone replacement therapy in primary hypothyroidism: a randomized trial comparing L-thyroxine plus liothyronine with L-thyroxine alone. Ann Intern Med 2005; 142:412-424.

11 Bunevicius R, Jakuboniene N, Jurkevicius R, Cernicat J, Lasas L, Prange AJ Jr: Thyroxine vs thyroxine plus triiodothyronine in treatment of hypothyroidism after thyroidectomy for Graves' disease. Endocrine 2002;18:129-133.

12 Grozinsky-Glasberg S, Fraser A, Nahshoni E, Weizman A, Leibovici L: Thyroxine-triiodothyronine combination therapy versus thyroxine monotherapy for clinical hypothyroidism: meta-analysis of randomized controlled trials. J Clin Endocrinol Metab 2006;91:2592 2599.

13 Carr D, McLeod DT, Parry G, Thornes HM: Fine adjustment of thyroxine replacement dosage: comparison of the thyrotrophin releasing hormone test using a sensitive thyrotrophin assay with measurement of free thyroid hormones and clinical assessment. Clin Endocrinol (Oxf) 1988;28:325-333.

14 Appelhof BC, Fliers E, Wekking EM, Schene AH, Huyser J, Tijssen JG, Endert E, van Weert HC, Wiersinga WM: Combined therapy with levothyroxine and liothyronine in two ratios, compared with levothyroxine monotherapy in primary hypothyroidism: a double-blind, randomized, controlled clinical trial. J Clin Endocrinol Metab 2005;90:2666-2674.

15 Celi FS, Zemskova M, Linderman JD, Smith S, Drinkard B, Sachdev V, Skarulis MC, Kozlosky M, Csako G, Costello R, Pucino F: Metabolic effects of liothyronine therapy in hypothyroidism: a randomized, double-blind, crossover trial of liothyronine versus levothyroxine. J Clin Endocrinol Metab 2011;96: 3466-3474.

-16 Hoang TD, Olsen CH, Mai VQ, Clyde PW, Shakir MK: Desiccated thyroid extract compared with levothyroxine in the treatment of hypothyroidism: a randomized, doubleblind, crossover study. J Clin Endocrinol Metab 2013;98:1982-1990.

-17 Panicker V, Saravanan P, Vaidya B, Evans J, Hattersley AT, Frayling TM, Dayan CM: Common variation in the $\mathrm{DIO} 2$ gene predicts baseline psychological well-being and response to combination thyroxine plus triiodothyronine therapy in hypothyroid patients. J Clin Endocrinol Metab 2009;94:1623-1629.

-18 Friesema EC, Jansen J, Jachtenberg JW, Visser WE, Kester MH, Visser TJ: Effective cellular uptake and efflux of thyroid hormone by human monocarboxylate transporter 10. Mol Endocrinol 2008;22:1357-1369.
19 van der Deure WM, Peeters RP, Visser TJ: Genetic variation in thyroid hormone transporters. Best Pract Res Clin Endocrinol Metab 2007;21:339-350.

20 Dayan CM, Panicker V: Novel insights into thyroid hormones from the study of common genetic variation. Nat Rev Endocrinol 2009;5: 211-218.

21 Nishimura M, Naito S: Tissue-specific mRNA expression profiles of human solute carrier transporter superfamilies. Drug Metab Pharmacokinet 2008;23:22-44.

22 Visser TJ: Cellular uptake of thyroid hormones; in: De Groot LJ, Chrousos G, Dungan K, Feingold KR, Grossman A, Hershman JM, Koch C, Korbonits M, McLachlan R, New M, Purnell J, Rebar R, Singer F, Vinik A (eds): Endotext [Internet]. South Dartmouth, MDText.com, Inc., 2000- (last update: June 15, 2016).

23 Steffensen R, Baech J, Nielsen KR: Allelic discrimination by TaqMan-PCR for genotyping of human neutrophil antigens. Methods Mol Biol 2015;1310:205-212.

24 Rodriguez S, Gaunt TR, Day IN: HardyWeinberg equilibrium testing of biological ascertainment for Mendelian randomization studies. Am J Epidemiol 2009;169:505-514.

25 Peeters RP, van den Beld AW, Attalki H, Toor H, de Rijke YB, Kuiper GG, Lamberts SW, Janssen JA, Uitterlinden AG, Visser TJ: A new polymorphism in the type II deiodinase gene is associated with circulating thyroid hormone parameters. Am J Physiol Endocrinol Metab 2005;289:E75-E81.

- 26 Peeters RP, van Toor H, Klootwijk W, de Rijke YB, Kuiper GG, Uitterlinden AG, Visser TJ: Polymorphisms in thyroid hormone pathway genes are associated with plasma TSH and iodothyronine levels in healthy subjects. J Clin Endocrinol Metab 2003;88:2880-2888.

-27 Appelhof BC, Peeters RP, Wiersinga WM, Visser TJ, Wekking EM, Huyser J, Schene AH, Tijssen JG, Hoogendijk WJ, Fliers E: Polymorphisms in type 2 deiodinase are not associated with well-being, neurocognitive functioning, and preference for combined thyroxine/3,5,3'-triiodothyronine therapy. J Clin Endocrinol Metab 2005;90:6296-6299.

28 de Jong FJ, Peeters RP, den Heijer T, van der Deure WM, Hofman A, Uitterlinden AG, Visser TJ, Breteler MM: The association of polymorphisms in the type 1 and 2 deiodinase genes with circulating thyroid hormone parameters and atrophy of the medial temporal lobe. J Clin Endocrinol Metab 2007;92:636640.

29 Gumieniak O, Perlstein TS, Williams JS, Hopkins PN, Brown NJ, Raby BA, Williams GH: Ala92 type 2 deiodinase allele increases risk for the development of hypertension. Hypertension 2007;49:461-466.
30 Panicker V, Cluett C, Shields B, Murray A, Parnell KS, Perry JR, Weedon MN, Singleton A, Hernandez D, Evans J, Durant C, Ferrucci L, Melzer D, Saravanan P, Visser TJ, Ceresini G, Hattersley AT, Vaidya B, Dayan CM, Frayling TM: A common variation in deiodinase 1 gene DIO1 is associated with the relative levels of free thyroxine and triiodothyronine. J Clin Endocrinol Metab 2008;93:3075-3081.

31 Mentuccia D, Thomas MJ, Coppotelli G, Reinhart LJ, Mitchell BD, Shuldiner AR, Celi FS: The Thr92Ala deiodinase type 2 (DIO2) variant is not associated with type 2 diabetes or indices of insulin resistance in the old order of Amish. Thyroid 2005;15:1223-1227.

32 Torlontano M, Durante C, Torrente I, Crocetti U, Augello G, Ronga G, Montesano T, Travascio L, Verrienti A, Bruno R, Santini S, D'Arcangelo P, Dallapiccola B, Filetti S, Trischitta V: Type 2 deiodinase polymorphism (threonine 92 alanine) predicts L-thyroxine dose to achieve target thyrotropin levels in thyroidectomized patients. J Clin Endocrinol Metab 2008;93:910-913.

33 Butler PW, Smith SM, Linderman JD, Brychta RJ, Alberobello AT, Dubaz OM, Luzon JA, Skarulis MC, Cochran CS, Wesley RA, Pucino F, Celi FS: The Thr92Ala $5^{\prime}$ type 2 deiodinase gene polymorphism is associated with a delayed triiodothyronine secretion in response to the thyrotropin-releasing hormone-stimulation test: a pharmacogenomic study. Thyroid 2010;20:1407-1412.

34 Fadeyev VV, Madiyarova M, Morgunova: Evaluation the association of polymorphismes in DIO1 and DIO2 genes with mental, biochemical parameters and quality of life in women with primary hypothyroidism (abstract OP77). 38th Annual Meeting of the European Thyroid Association. Santiago de Compostela, September 2014.

35 Heemstra KA, Hoftijzer HC, van der Deure WM, Peeters RP, Fliers E, Appelhof BC, Wiersinga WM, Corssmit EP, Visser TJ, Smit JW: Thr92Ala polymorphism in the type $2 \mathrm{de}$ iodinase is not associated with T4 dose in athyroid patients or patients with Hashimoto thyroiditis. Clin Endocrinol (Oxf) 2009;71: 279-283.

36 Roef G, Taes Y, Toye K, Goemaere S, Fiers T, Verstraete A, Kaufman JM: Heredity and lifestyle in the determination of between-subject variation in thyroid hormone levels in euthyroid men. Eur J Endocrinol 2013;169:835844.

37 Wouters HJ, van Loon HC, van der Klauw MM, Elderson MF, Slagter SN, Muller KA, Kema IP, Links TP, Vliet-Ostaptchouk JV, Wolffenbuttel BH: No effect of the Thr92Ala polymorphism of deiodinase- 2 on thyroid hormone parameters, health-related quality of life, and cognitive functioning in a large population-based cohort study. Thyroid 2017;27:147-155. 
38 Yalakanti D, Dolia PB: Association of type II $5^{\prime}$ monodeiodinase Thr92Ala single nucleotide gene polymorphism and circulating thyroid hormones among type 2 diabetes mellitus patients. Indian J Clin Biochem 2016;31: 152-161.

-39 Peltsverger MY, Butler PW, Alberobello AT, Smith S, Guevara Y, Dubaz OM, Luzon JA, Linderman J, Celi FS: The $-258 \mathrm{~A} / \mathrm{G}$ (SNP rs12885300) polymorphism of the human type 2 deiodinase gene is associated with a shift in the pattern of secretion of thyroid hormones following a TRH-induced acute rise in TSH. Eur J Endocrinol 2012;166:839-845.

40 Medici M, van der Deure WM, Verbiest M, Vermeulen SH, Hansen PS, Kiemeney LA, Hermus AR, Breteler MM, Hofman A, Hegedus L, Kyvik KO, den Heijer M, Uitterlinden AG, Visser TJ, Peeters RP: A large-scale association analysis of 68 thyroid hormone pathway genes with serum TSH and FT4 levels. Eur J Endocrinol 2011;164:781-788.

41 Roef GL, Rietzschel ER, De Meyer T, Bekaert S, De Buyzere ML, Van daele C, Toye K, Kaufman JM, Taes YE: Associations between single nucleotide polymorphisms in thyroid hormone transporter genes (MCT8, MCT10 and OATP1C1) and circulating thyroid hormones. Clin Chim Acta 2013;425:227-232.

42 Bianco AC, Salvatore D, Gereben B, Berry MJ, Larsen PR: Biochemistry, cellular and molecular biology, and physiological roles of the iodothyronine selenodeiodinases. Endocr Rev 2002;23:38-89.

43 Carlé A, Pedersen IB, Knudsen N, Perrild H, Ovesen L, Andersen S, Laurberg P: Hypothyroid symptoms fail to predict thyroid insufficiency in old people: a population-based casecontrol study. Am J Med 2016;129:10821092.

44 Carlé A, Pedersen IB, Knudsen N, Perrild H, Ovesen L, Laurberg P: Hypothyroid symptoms and the likelihood of overt thyroid failure: a population-based case-control study. Eur J Endocrinol 2014;171:593-602.

45 Medici M, van der Deure WM, Verbiest M, Vermeulen SH, Hansen PS, Kiemeney LA, Hermus AR, Breteler MM, Hofman A, Hegedüs L, Kyvik KO, den Heijer M, Uitterlinden AG, Visser TJ, Peeters RP: A large-scale association analysis of 68 thyroid hormone pathway genes with serum TSH and FT4 levels. Eur J Endocrinol 2011;164:781-788.

46 Taylor PN, Porcu E, Chew S, et al: Whole-genome sequence-based analysis of thyroid function. Nat Commun 2015;6:5681.

47 Wirth EK, Schweizer U, Kohrle J: Transport of thyroid hormone in brain. Front Endocrinol (Lausanne) 2014;5:98.

48 Friesema EC, Visser TJ, Borgers AJ, Kalsbeek A, Swaab DF, Fliers E, Alkemade A: Thyroid hormone transporters and deiodinases in the developing human hypothalamus. Eur J Endocrinol 2012;167:379-386.

49 Wacholder S, Chanock S, Garcia-Closas M, El Ghormli L, Rothman N: Assessing the probability that a positive report is false: an approach for molecular epidemiology studies. J Natl Cancer Inst 2004;96:434-442.

50 Rothman KJ, Greenland S: Modern Epidemiology, ed 2. Philadelphia, Lippincott-Raven Publishers, 1988.

51 Hill AB: The environment and disease: association or causation? Proc R Soc Med 1965;58: 295-300. 